\title{
Optimising the Benefits of SGLT2 Inhibitors for Type 1 Diabetes
}

Marc Evans $\cdot$ Debbie Hicks $\cdot$ Dipesh Patel $\cdot$ Vinod Patel ·

Phil McEwan · Umesh Dashora

Received: September 24, 2019 / Published online: December 7, 2019

(C) The Author(s) 2019

\section{ABSTRACT}

Sodium-glucose cotransporter 2 (SGLT2) inhibitor clinical studies in type 1 diabetes mellitus (T1DM) have demonstrated reduced HbA1c and lower glucose variability with increased time in optimal glucose range as well as additional benefits of reductions in weight and insulin dose without increasing the incidence of

Enhanced Digital Features To view enhanced digital features for this article go to https://doi.org/10.6084/ m9.figshare.9896615.

Electronic supplementary material The online version of this article (https://doi.org/10.1007/s13300019-00728-6) contains supplementary material, which is available to authorized users.

M. Evans ( $\square)$

Diabetes Resource Centre, University Hospital

Llandough, Cardiff, UK

e-mail: marclyndon1@hotmail.com

D. Hicks

Medicus Health Partners, Enfield, London, UK

D. Patel

Department of Diabetes, Division of Medicine, University College London, Royal Free NHS Trust, London, UK

V. Patel

Warwick Medical School, University of Warwick, George Eliot Hospital NHS Trust, Nuneaton, UK hypoglycaemia. However, the appropriate use of SGLT2 inhibitor therapies within clinical practise to treat people with T1DM remains unclear. In this article we have used consensus expert opinion alongside the available evidence, product indication and most recent clinical guidance to provide support for the diabetes healthcare community regarding the appropriate use of SGLT2 inhibitors, focussing on specific considerations for appropriate prescribing of dapagliflozin within the T1DM management pathway. Its purpose is to provide awareness of the issues surrounding treatment with dapagliflozin in T1DM as well as offer practical guidance that also includes a checklist tool for appropriate dapagliflozin prescribing. The checklist aims to support clinicians in identifying those people with T1DM most likely to benefit from dapagliflozin treatment as well as situations where caution may be required.

Funding: AstraZeneca UK Ltd.

\section{P. McEwan}

Health Economics and Outcomes Research Ltd.,

Cardiff, UK

U. Dashora

East Sussex Healthcare NHS Trust, Eastbourne, UK 
Keywords: Dapagliflozin; $\quad$ Risk/benefit; Sodium-glucose transporter 2 inhibitor; Type 1 diabetes mellitus

\section{INTRODUCTION}

Globally, the annual incidence of type 1 diabetes mellitus (T1DM) is increasing by approximately $2-3 \%$ per year $[1,2]$. T1DM is a consequence of the autoimmune or non-immune destruction of insulin-producing pancreatic $\beta$-cells and results in an increase in glycated haemoglobin (HbA1c) [3-5]. Strict glycaemic control in people with T1DM has been shown to reduce the risk of microvascular (e.g. diabetic retinopathy, nephropathy and neuropathy) and macrovascular (e.g. coronary artery disease and peripheral vascular disease) complications [6-8].

Optimal glycaemic control requires administration of insulin that simulates physiological insulin secretion and typically involves one or two subcutaneous injections of basal insulin daily to control glycaemia between meals and overnight and subcutaneous injections of prandial insulin at mealtime to control glycaemia following meals [9]. Improvements in therapeutic approaches, such as insulin pumps, continuous glucose monitoring (CGM) and hybrid closed-loop systems, are now also increasingly used [10]. These advances in diabetes technology have improved glycaemic control and resulted in overall decreases in the rates of hypoglycaemia and weight gain that were highlighted as major side effects of intensive insulin therapy in the landmark Diabetes Control and Complications Trial (DCCT) [11-13]. However, despite the improvements, hypoglycaemia and weight gain remain significant adverse events associated with insulin therapy $[14,15]$. Furthermore, the vast majority of people with T1DM still do not achieve recommended glycaemic targets; only $29.9 \%$ of people with T1DM achieved HbA1c levels $\leq 58 \mathrm{nmol} / \mathrm{mol}(7.5 \%)$ in England and Wales, 2017-2018 [16]. Thus, there is an unmet need, and great interest within the diabetes care community, regarding adjunct therapies to improve glycaemic control without increasing the risk of hypoglycaemia and weight gain.
Until recently there have been no licensed treatment options available in the UK for people with T1DM that are inadequately controlled by insulin alone. Whilst unlicensed use of metformin occurs in clinical practice, results of the REMOVAL trial (a double-blind, placebo-controlled multicentre trial assessing the long-term effects of metformin added to insulin therapy in people with T1DM), although demonstrating a benefit in terms of weight loss, did not support a role for metformin to improve glycaemic control or to reduce insulin dose [17]. Furthermore, a meta-analysis of 13 randomised controlled trials (RCTs) demonstrated that metformin has not consistently shown glycaemic benefits in T1DM [18].

A number of studies have investigated the effect of alpha-glucosidase inhibitors, pioglitazone, glucagon-like peptide (GLP)-1 receptor agonists or dipeptidyl peptidase (DPP)-4 inhibitors in T1DM [19-26], but the inconsistent results have not supported the use of these treatments in clinical practise. For example, the DPP-4 inhibitor sitagliptin has been shown to reduce insulin requirements and improve metabolic control without increasing the risk of hypoglycaemia in people with T1DM in some studies [27, 28], whilst no major benefit has been observed in other studies $[29,30]$.

Sodium-glucose cotransporter 2 (SGLT2) inhibitors are particularly attractive for adjunctive use in T1DM, as they are oral agents that reduce the reabsorption of glucose in the kidney and increase its excretion via the urine, a mechanism that is independent of islet cell functionality [31-33]. SGLT2 inhibitor clinical studies, conducted in people with T1DM, have demonstrated reduced HbA1c and lower glucose variability with increased time in optimal glucose range [i.e. glucose levels $70-180 \mathrm{mg} / \mathrm{dl}$ $(3.9-10 \mathrm{mmol} / \mathrm{l})]$ as well as additional benefits of reductions in weight and insulin dose without increasing the incidence of hypoglycaemia [34-41]. However, SGLT2 inhibitors are not deemed suitable for everyone with T1DM and so careful selection of appropriate people, with the development and dissemination of appropriate strategies to minimise the risk of adverse events, is essential and has already been the 
focus of activity within the diabetes care specialist community $[42,43]$.

Recently, there has been a growing literature base, including review articles and expert consensus guidance, focussing on the role of SGLT2 inhibitors in T1DM. However, the guidance provided is often conflicting and many of the recommendations may not accurately reflect current licence indications. As a consequence, there is uncertainty in the clinical community regarding the efficacy, safety and appropriate use of SGLT2 inhibitors for T1DM. We have therefore sought to contextualise the available SGLT2 inhibitor data, examine the risk-benefit profile and provide guidance on selecting appropriate people for SGLT2 inhibitor treatment and practical approaches for healthcare professionals who care for people with T1DM, focussing on specific considerations for appropriate SGLT2 inhibitor prescribing within the T1DM management pathway in the UK.

US Food and Drug Administration (FDA) and European Medicines Agency (EMA) approval has been granted to four SGLT2 inhibitors to date-canagliflozin, dapagliflozin, empagliflozin and ertugliflozin (the dual SGLT1/SGLT2 inhibitor sotagliflozin also has EMA approval), and in Japan, three other SGLT2 inhibitorsipragliflozin, luseogliflozin and tofogliflozinhave been approved [44]. All of these approvals are for the treatment of type 2 diabetes mellitus (T2DM). Dapagliflozin is the first SGLT2 inhibitor to have its marketing authorisation extended to T1DM [45]. Furthermore, it also has approval from the National Institute for Health and Care Excellence (NICE) for T1DM, in which dapagliflozin was found to be a highly cost-effective treatment option in people with T1DM inadequately controlled by insulin alone, with an incremental cost-effectiveness ratio (ICER) of $£ 13,775$ per quality-adjusted life year (QALY) gained for dapagliflozin $5 \mathrm{mg}$ compared with standard of care [46]. Following the positive NICE guidance, the Scottish Medicines Consortium (SMC) has recommended dapagliflozin for patients with inadequately controlled T1DM in Scotland. This positive decision means that appropriate patients with uncontrolled T1DM in Scotland will have access to dapagliflozin, as an adjunct to insulin, through the NHS with funding expected to be available from November 2019 [47].

The guidance provided in this article is based on the available evidence, as well as from consensus expert opinion, in accordance with the label indication for dapagliflozin. The guidance aims to be of value to a wide audience of healthcare professionals working in the management of T1DM. Its purpose is to provide awareness of the issues concerning SGLT2 inhibitor therapy in T1DM as well as practical guidance that also includes a checklist tool to support clinicians in identifying those people with T1DM most likely to benefit from dapagliflozin treatment as well as situations where caution may be required.

This article is based on previously conducted studies and does not contain any studies with human participants or animals performed by any of the authors.

\section{EFFICACY AND SAFETY OF SGLT2 INHIBITORS IN PEOPLE WITH T1DM}

Several SGLT2 inhibitors have completed phase 3 clinical trials to evaluate the efficacy and safety of their use as adjunctive therapy in T1DM (Table 1). The empagliflozin-focussed EASE (Empagliflozin as Adjunctive to inSulin thErapy) programme comprised the EASE2 (52 weeks) and EASE3 (26 weeks) trials [34]. EASE2 participants were randomised to one of two doses of empagliflozin (10 or $25 \mathrm{mg}$ ) or placebo while EASE3 participants were randomised to one of three doses of empagliflozin $(2.5,10$ or $25 \mathrm{mg})$ or placebo. In EASE2, in the empagliflozin 10 and $25 \mathrm{mg}$ groups the placeboadjusted changes in HbA1c were -0.39 and $-0.45 \%$ and the placebo-adjusted changes in body weight were -3.2 and $-3.6 \mathrm{~kg}$. In EASE3, in the empagliflozin 2.5, 10 and $25 \mathrm{mg}$ groups the placebo-adjusted changes in HbA1c were $-0.28,-0.45$ and $-0.52 \%$ and the placeboadjusted changes in body weight were -1.8 , -3.0 and $-3.4 \mathrm{~kg}$. All placebo-adjusted changes in HbA1c and body weight for both EASE2 and EASE3 were statistically significant with $p<0.0001$ (Table 1). In a pooled analysis of adverse events, an important finding was the 
Table 1 Phase 3 SGLT2 inhibitor clinical trials in T1DM

\begin{tabular}{|c|c|c|c|c|c|c|c|}
\hline Trial & $N$ & $\begin{array}{l}\text { Study } \\
\text { duration } \\
\text { (weeks) }\end{array}$ & Treatment & $\begin{array}{l}\text { Insulin dose } \\
\text { change vs. } \\
\text { placebo (\%) }\end{array}$ & $\begin{array}{l}\text { HbA1c } \\
\text { change vs. } \\
\text { placebo (\%) }\end{array}$ & $\begin{array}{l}\text { Body weight } \\
\text { change vs. } \\
\text { placebo }(\mathbf{k g})\end{array}$ & $\begin{array}{l}\text { Incidence } \\
\text { DKA (\%) }\end{array}$ \\
\hline \multirow[t]{3}{*}{$\begin{array}{l}\text { DEPICT1 } \\
{[39]}\end{array}$} & 833 & 52 & $\begin{array}{l}\text { Dapagliflozin } \\
5 \mathrm{mg}\end{array}$ & $-8.8^{\mathrm{a}}$ & -0.33 & -2.56 & 4.0 \\
\hline & & & $\begin{array}{l}\text { Dapagliflozin } \\
10 \mathrm{mg}\end{array}$ & $-13.2^{\mathrm{a}}$ & -0.36 & -3.90 & 3.4 \\
\hline & & & Placebo & & & & 1.9 \\
\hline \multirow[t]{3}{*}{$\begin{array}{l}\text { DEPICT2 } \\
{[40]}\end{array}$} & 815 & 24 & $\begin{array}{l}\text { Dapagliflozin } \\
5 \mathrm{mg}\end{array}$ & -10.8 & -0.37 & -3.21 & 2.6 \\
\hline & & & $\begin{array}{l}\text { Dapagliflozin } \\
10 \mathrm{mg}\end{array}$ & -11.1 & -0.42 & -3.74 & 2.2 \\
\hline & & & Placebo & & & & 0 \\
\hline \multirow[t]{3}{*}{ EASE2 [34] } & 730 & 52 & $\begin{array}{l}\text { Empagliflozin } \\
10 \mathrm{mg}\end{array}$ & -12.0 & -0.39 & -3.2 & $4.3^{\mathrm{b}}$ \\
\hline & & & $\begin{array}{l}\text { Empagliflozin } \\
25 \mathrm{mg}\end{array}$ & -12.9 & -0.45 & -3.6 & $3.3^{\mathrm{b}}$ \\
\hline & & & Placebo & & & & 1.2 \\
\hline \multirow[t]{4}{*}{ EASE3 [34] } & 975 & 26 & $\begin{array}{l}\text { Empagliflozin } \\
2.5 \mathrm{mg}\end{array}$ & -6.4 & -0.28 & -1.8 & 0.8 \\
\hline & & & $\begin{array}{l}\text { Empagliflozin } \\
10 \mathrm{mg}\end{array}$ & -9.5 & -0.45 & -3.0 & $4.3^{\mathrm{b}}$ \\
\hline & & & $\begin{array}{l}\text { Empagliflozin } \\
25 \mathrm{mg}\end{array}$ & -12.6 & -0.52 & -3.4 & $3.3^{\mathrm{b}}$ \\
\hline & & & Placebo & & & & 1.2 \\
\hline \multirow[t]{3}{*}{$\begin{array}{l}\text { inTANDEM1 } \\
{[35]}\end{array}$} & 793 & 52 & $\begin{array}{l}\text { Sotagliflozin } \\
200 \mathrm{mg}\end{array}$ & -8.0 & -0.25 & -3.14 & 3.4 \\
\hline & & & $\begin{array}{l}\text { Sotagliflozin } \\
400 \mathrm{mg}\end{array}$ & -12.6 & -0.31 & -4.32 & 4.2 \\
\hline & & & Placebo & & & & 0.4 \\
\hline \multirow[t]{3}{*}{$\begin{array}{l}\text { inTANDEM2 } \\
{[36]}\end{array}$} & 782 & 52 & $\begin{array}{l}\text { Sotagliflozin } \\
200 \mathrm{mg}\end{array}$ & -6.3 & -0.37 & -2.18 & 2.3 \\
\hline & & & $\begin{array}{l}\text { Sotagliflozin } \\
400 \mathrm{mg}\end{array}$ & -8.2 & -0.35 & -2.92 & 3.4 \\
\hline & & & Placebo & & & & 0 \\
\hline
\end{tabular}


Table 1 continued

\begin{tabular}{|c|c|c|c|c|c|c|c|}
\hline Trial & $N$ & $\begin{array}{l}\text { Study } \\
\text { duration } \\
\text { (weeks) }\end{array}$ & Treatment & $\begin{array}{l}\text { Insulin dose } \\
\text { change vs. } \\
\text { placebo (\%) }\end{array}$ & $\begin{array}{l}\text { HbA1c } \\
\text { change vs. } \\
\text { placebo (\%) }\end{array}$ & $\begin{array}{l}\text { Body weight } \\
\text { change vs. } \\
\text { placebo (kg) }\end{array}$ & $\begin{array}{l}\text { Incidence } \\
\text { DKA (\%) }\end{array}$ \\
\hline \multirow[t]{2}{*}{$\begin{array}{l}\text { inTANDEM3 } \\
{[37]}\end{array}$} & 1402 & 24 & $\begin{array}{l}\text { Sotagliflozin } \\
\quad 400 \mathrm{mg}\end{array}$ & -9.7 & -0.46 & -2.98 & 3.0 \\
\hline & & & Placebo & & & & 0.6 \\
\hline
\end{tabular}

${ }^{a}$ DEPICT1 24-week data

b Pooled EASE2 and EASE3 data

higher incidence of diabetic ketoacidosis (DKA) in the empagliflozin groups: $25 \mathrm{mg}, 3.3 \%$; $10 \mathrm{mg}$, 4.3\%; placebo, $1.2 \%$. Most cases of DKA were associated with a precipitating factor such as infection or reduced insulin dose. For both EASE2 and EASE3 CGM-derived glucose time in range $[70-180 \mathrm{mg} / \mathrm{dl} \quad(3.9-10 \mathrm{mmol} / \mathrm{l})]$ significantly increased by approximately $3 \mathrm{~h}$ a day with empagliflozin compared with placebo; placebo-adjusted change (hours/day) from baseline of +3.0 for empagliflozin $25 \mathrm{mg}$ and +2.9 for empagliflozin $10 \mathrm{mg}$ in EASE2 and +2.6 for empagliflozin $25 \mathrm{mg}+1.8$ for empagliflozin $10 \mathrm{mg}$ and +1.0 for empagliflozin $2.5 \mathrm{mg}$ in EASE3.

Sotagliflozin is a dual SGLT1/2 inhibitor and reduces glucose reabsorption in the kidneys through SGLT2 inhibition as well as delaying dietary glucose absorption through SGLT1 inhibition in the intestinal tract. The safety and efficacy of sotagliflozin in T1DM were assessed in the inTANDEM1-3 studies. The inTandem 1 [35] and inTandem2 [36] trials evaluated two doses of sotagliflozin (200 and $400 \mathrm{mg}$ ) alongside placebo while the inTandem 3 trial [37] was a two-arm (400 mg sotagliflozin vs. placebo) study. Sotagliflozin was associated, across all three trials, with statistically significant $(p<0.001)$ reductions in HbA1c, weight and total daily insulin dose (Table 1). The primary end point for the inTandem3 trial, the proportion of participants achieving HbA1c $\leq 53 \mathrm{mmol} / \mathrm{mol}$ (7.0\%) without severe hypoglycaemia or DKA at the end of the study, was met by a significantly higher proportion of people in the sotagliflozin arm compared with placebo $(28.6 \%$ vs. $15.2 \%$; $p<0.001)$. Incidence of DKA was consistently higher in people receiving sotagliflozin compared with placebo across the three trials: $400 \mathrm{mg}, 3.0-4.2 \%$; $200 \mathrm{mg}, 2.3-3.4 \%$; placebo, $0-0.6 \%$. In pooled analyses of CGM data from inTandem 1 and inTandem2, compared with placebo an additional time in range of $1.3 \mathrm{~h} /$ day was demonstrated with sotagliflozin $200 \mathrm{mg}$ and $2.8 \mathrm{~h}$ /day with sotagliflozin $400 \mathrm{mg}$ [48].

The safety and efficacy of dapagliflozin in T1DM were investigated in the Dapagliflozin Evaluation in Patients with Inadequately Controlled Type 1 Diabetes (DEPICT) clinical trial programme, which comprised two studiesDEPICT1 (24-week short term plus 28 week extension) [38, 39] and DEPICT2 (24 weeks) [40]. Both DEPICT trials included two dapagliflozin groups (5 and $10 \mathrm{mg}$ ) and a placebo arm. Both trials demonstrated statistically significant $(p<0.0001)$ decreases in HbA1c, weight and total daily insulin dose. At week 52 in DEPICT1, the placebo-adjusted changes in $\mathrm{HbA1c}$ and weight in the dapagliflozin 5 and $10 \mathrm{mg}$ groups, respectively, were: HbA1c -0.33 and $-0.36 \%$; weight -2.95 and $-4.5 \mathrm{~kg}$. At week 24 in DEPICT2, the placebo-adjusted changes in HbA1c and weight in the dapagliflozin 5 and $10 \mathrm{mg}$ groups were similar to those reported in DEPICT1 (Table 1). An important finding was the higher incidence of DKA in the dapagliflozin groups compared with placebo for both DEPICT trials: $10 \mathrm{mg}, 2.2-3.4 \% ; 5 \mathrm{mg}$, $2.6-4.0 \%$; placebo, $0-1.9 \%$. The majority of the cases were a result of insulin pump failure or missed insulin dose and one case was as a consequence of excessive alcohol intake. All were resolved with standard of care. In pooled analyses of 24-week CGM data from DEPICT1 and 
DEPICT2, those receiving dapagliflozin $5 \mathrm{mg}$ or $10 \mathrm{mg}$ both spent more time in range over $24 \mathrm{~h}$ than those receiving the placebo; the adjusted mean change from baseline at week 24 was $6.5 \%$ with dapagliflozin $5 \mathrm{mg}, 8.1 \%$ with dapagliflozin $10 \mathrm{mg}$ and $-2.6 \%$ with placebo [41].

Based on the positive results from the DEPICT studies dapagliflozin $5 \mathrm{mg}$ received marketing approval in Europe in March 2019 as an adjunct to insulin in people with T1DM with a body mass index (BMI) $\geq 27 \mathrm{~kg} / \mathrm{m}^{2}$ (the BMI restriction reflects safety concerns around DKA risk in those with a lower BMI), when insulin alone does not provide adequate glycaemic control despite optimal insulin therapy $[45,49]$. It has also recently received SMC approval [47], and additionally has NICE approval following health economic analysis, which demonstrated the value of dapagliflozin as an adjunct treatment for people with T1DM at cost-effectiveness thresholds conventionally applied in the UK, with an estimated ICER per QALY gained (with the QALY gains being largely driven by the improved quality of life associated with weight reduction as opposed to the HbA1c reductions observed in the DEPICT studies) of between $£ 6385$ and $£ 19,122$ [46]. The impact of additional parameters, such as an increased time in range, on these estimations remains uncertain, even though there is a growing awareness that even small increments (5\%) in time in range, as measured by CGM and not necessarily reflected by significant changes in glycated haemoglobin levels, may have beneficial effects [50].

\section{BENEFIT-RISK PROFILE OF DAPAGLIFLOZIN}

The DEPICT trial results demonstrated a significant reduction in HbA1c from baseline in people in the dapagliflozin arm compared with those in the placebo arm. In addition, participants receiving dapagliflozin lost more weight than those in the placebo group. The reduction of weight is likely to be of importance for many people with T1DM and also has the potential to limit later cardiovascular risk. SGLT2 inhibitors have demonstrated a proven benefit for cardio- renal outcomes in T2DM. It remains unclear whether or not these benefits would be replicated in people with T1DM as the pathophysiology of cardiorenal disease may be different in T1DM. Therefore, despite the potential for cardio-renal benefits with SGLT2 inhibitors in T1DM, further evidence is required to verify this.

The overall adverse event profile for dapagliflozin use in people with T1DM was similar to dapagliflozin use in people with T2DM. The most common side effects reported with dapagliflozin $5 \mathrm{mg}$ across the DEPCIT clinical trial programme for T1DM were an increased incidence of genital mycotic infections (10-16\% compared with $2-3 \%$ for placebo) and urinary tract infections (UTIs) (7-12\% compared with $4-8 \%$ for placebo). The increased risk of genital mycotic infections associated with SGLT2 inhibitors has also been reported in a real-world setting [51]. Although these infections have the potential to significantly impact quality of life, most are mild-to-moderate infections that can be easily managed and do not necessitate dapagliflozin discontinuation.

SGLT2 inhibitors are associated with an increased risk for Fournier's gangrene, an extremely rare but serious and potentially lifethreatening bacterial infection of the external genitalia, perineum and perianal region. Between March 2013 and January 2019, 55 cases of Fournier's gangrene have been reported in people receiving SGLT2 inhibitors (16 of which were on dapagliflozin) compared with 19 cases reported over 35 years in people taking other diabetes drugs [52].

Another serious complication associated with SGLT2 inhibitors is DKA-a medical emergency that occurs when a severe lack of insulin leads to the use of alternative energy sources such as fat, resulting in the production of acidic ketone bodies. Despite DKA risk mitigation strategies in DEPICT, DKA rates in people receiving dapagliflozin were as high as 3-4\% while rates in the placebo group were $<2 \%$. The risk of DKA may be even higher in routine clinical settings where monitoring is likely to be less stringent than in clinical trials. It has been suggested that the increased risk of DKA is predominantly due to the failure of people 
receiving an SGLT2 inhibitor to promptly recognise early metabolic decompensation, which occurs at lower than usual glucose levels [53]. Also, the reduction in insulin dose may trigger ketogenesis in some people. Important strategies in mitigating DKA risk with an SGLT2 inhibitor include appropriate education of both people with T1DM and healthcare professionals, concerning the risk of DKA and how to minimise this risk, and the selection of appropriate people for treatment.

\section{APPROPRIATE PRESCRIBING OF DAPAGLIFLOZIN IN T1DM}

Selecting appropriate people with T1DM for SGLT2 inhibitor treatment is critical for minimising the risks and maximising the potential benefits associated with this treatment. Yet, there is confusion surrounding which people with T1DM are most suitable.

The NICE guidance identifies dapagliflozin as a treatment with both clinical and economic value in people with T1DM [46]. Furthermore, the guidance provides recommendations for when prescribing of dapagliflozin would be appropriate in T1DM. Dapagliflozin with insulin is recommended for adults with T1DM with a BMI of $\geq 27 \mathrm{~kg} / \mathrm{m}^{2}$, when insulin alone does not provide adequate glycaemic control despite optimal insulin therapy, only if they are on insulin doses of $>0.5$ units $/ \mathrm{kg}$ of body weight/day (the insulin dose restriction reflects safety concerns around DKA risk in those with lower insulin needs) and they have completed a structured education programme (including information about the risk of DKA, how to recognise risk factors for DKA and its signs and symptoms, how and when to monitor blood ketone levels, what actions to take for elevated blood ketones) and treatment is started and supervised in a hospital diabetes clinic. Within this guidance, it is suggested that HbA1c levels should be measured after 6 months and regularly after this. Treatment with dapagliflozin in combination with insulin compared with insulin alone in people with T1DM remains cost effective (ICER per QALY gain $<£ 20,000$ ) even in a scenario of no significant improvement in glucose control, largely driven by reductions in insulin dose and body weight. However, in the absence of any sustained improvement in blood glucose control (defined as a fall in HbA1c level of $\geq 0.3 \%$ ), the current NICE guidance recommends that dapagliflozin should be discontinued, as the harms (risk of DKA) outweigh the benefits in this situation.

The SMC guidance applies to the full dapagliflozin marketing authorisation and does not include a restriction to patients with insulin needs $>0.5$ units $/ \mathrm{kg}$ per day. It also does not apply to the stopping rules that are recommended in the NICE guidance. Analysis of data from DEPICT suggests that the majority of patients in practice are on insulin doses $>0.5$ units/kg per day, and most patients treated with dapagliflozin will achieve an HbA1c reduction of $\geq 0.3 \%$ at 6 months. Therefore, the differences in recommendation wording between NICE and SMC are not expected to lead to substantial inequality of access among England, Wales and Scotland.

Based on the DEPICT data and the current label indication for dapagliflozin as well as recent clinical guidance, we have formed consensus regarding appropriate prescribing of dapagliflozin in T1DM and developed a checklist that offers a quick reference guide for clinicians to identify the people most likely to benefit from dapagliflozin treatment as well as situations where caution may be required (Fig. 1). The checklist follows a traffic light system whereby we recommend that clinicians should consider prescribing dapagliflozin for people in the green section, not consider prescribing dapagliflozin for people in the red section and possibly consider prescribing dapagliflozin with caution for people in the amber section.

\section{Consider Prescribing Dapagliflozin}

People most suitable for dapagliflozin in T1DM are likely to be those with a BMI $\geq 27 \mathrm{~kg} / \mathrm{m}^{2}$, established on stable optimised insulin therapy (i.e. not recently diagnosed) and with high insulin needs (i.e. $>0.5$ units $/ \mathrm{kg}$ of body weight/day).

One of the most important criteria for determining if someone is suitable for 


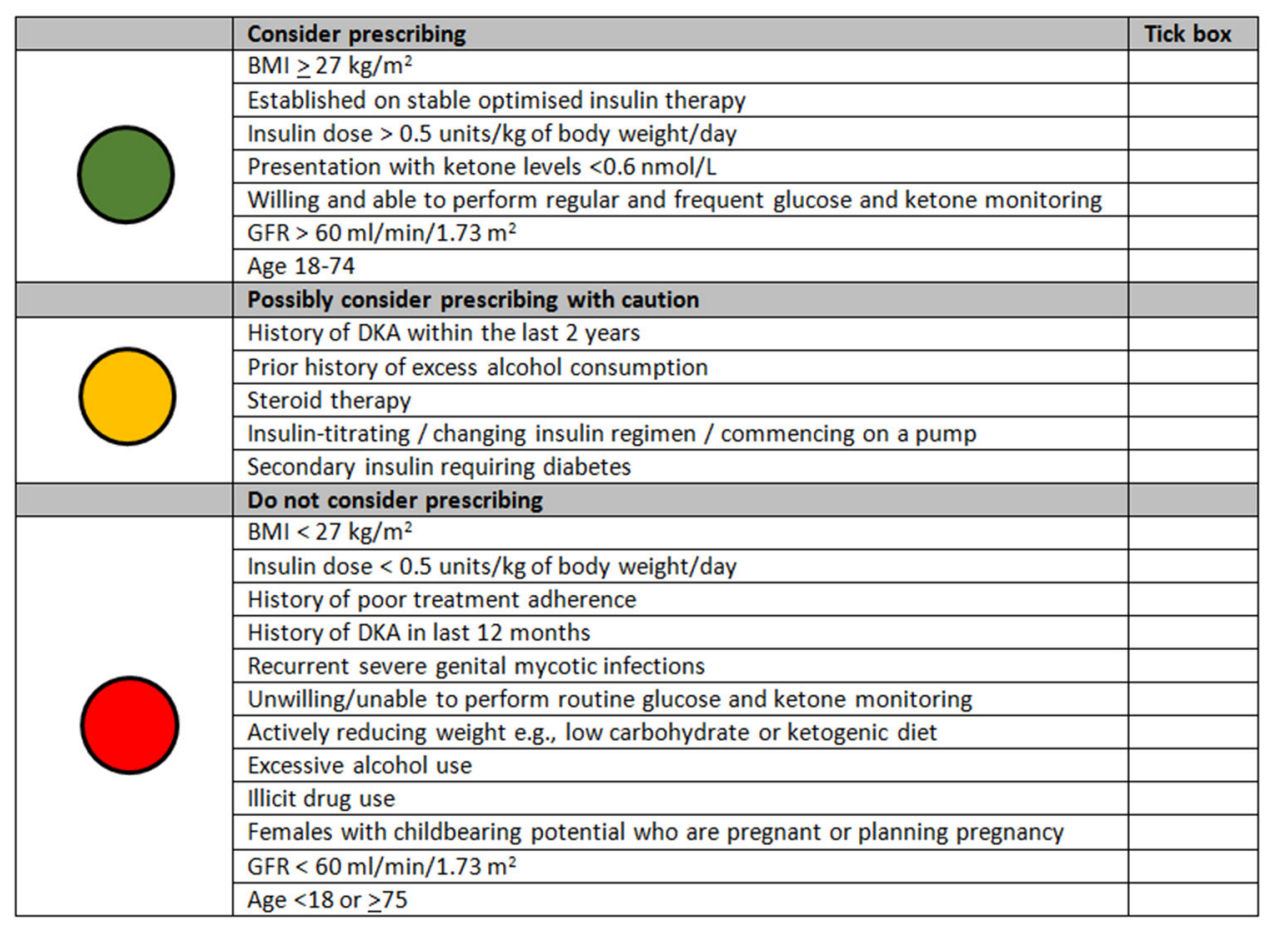

Fig. 1 Checklist for appropriate prescribing of dapagliflozin in T1DM. BMI body mass index, DKA diabetic ketoacidosis, $G F R$ glomerular filtration rate

dapagliflozin treatment is normal blood ketone levels $(<0.6 \mathrm{mmol} / \mathrm{l})$. Urine ketone monitoring is not advisable as it is not deemed to be as accurate as blood ketone testing, since urine test results are indicative of blood ketone levels in the past, and accuracy is also affected by hydration levels and kidney function [54]. The willingness/ability to follow prescribed regimens for monitoring ketones and responding appropriately to elevated ketone levels must also be considered.

Additional criteria for which people with T1DM should be prescribed dapagliflozin include glomerular filtration rate (GFR) $>60 \mathrm{ml} / \mathrm{min} /$ $1.73 \mathrm{~m}^{2}$ (as dapagliflozin efficacy is dependent on renal function) and age 18-74 years (as the DEPICT clinical trial programme was conducted in this age group).

\section{Possibly Consider Prescribing Dapagliflozin with Caution}

There are a number of groups of people for which dapagliflozin probably should not be prescribed. However, the available data are unclear, and we would suggest proceeding on an individual basis with caution for people that fall into these categories. People with T1DM that should be prescribed dapagliflozin with caution include those with a prior history of DKA (i.e. within the last 2 years), prior history of excess alcohol consumption or currently prescribed steroid therapy. Clinicians should also proceed with caution if prescribing dapagliflozin to people with T1DM who are currently insulin-titrating, changing their insulin regimen or commencing on an insulin pump. There is some evidence from the clinical trials to suggest that SGLT2 inhibitor-related DKA may occur more frequently in people who are pumptreated compared with those treated with insulin injections. For example, in the sotagliflozin $400 \mathrm{mg}$ arm of inTANDEM1, inTANDEM2 and inTANDEM3, DKA occurred in 4,5 and $4 \%$ of people who were pump-treated compared with 2,1 and $3 \%$ of people who received insulin by injection [35-37]. In most cases DKA will be accompanied by high glucose levels; however, it is not unusual for people on insulin pumps to 
develop DKA despite having low or normal blood glucose levels.

Secondary insulin-requiring diabetes (diabetes that results as a consequence of another medication, endocrine disease or hereditary disease, e.g. pancreatic diabetes, which results in insulin deficiency following pancreatitis or pancreatectomy) has not been represented in the SGLT2 inhibitor clinical trial programmes. Therefore, as the role of dapagliflozin in this subgroup is uncertain we suggest proceeding with caution in such situations, but applying the same caveats as in those individuals with T1DM.

\section{Do Not Consider Prescribing Dapagliflozin}

In line with the label indication for dapagliflozin we do not recommend that dapagliflozin be prescribed to people with T1DM with BMI $<27 \mathrm{~kg} / \mathrm{m}^{2}$ or those with low insulin needs ( $<0.5 \mathrm{units} / \mathrm{kg}$ of body weight/day). The aim of both these criteria is to manage the safety concerns of an increased risk of DKA associated with dapagliflozin in these subgroups. Based on available data as well as consensus we have developed further criteria to define additional groups that should not be offered treatment with dapagliflozin.

People with T1DM who have a history of poor treatment adherence such as missed insulin doses, have a history of DKA within the last 12 months, have had recurrent severe genital mycotic infections or display low engagement with their diabetes regimen (i.e. unwilling/unable to perform routine glucose and ketone monitoring) are at high risk of DKA when on SGLT2 inhibitor therapy and should not be prescribed dapagliflozin treatment. Also, people with certain lifestyle behaviours that increase DKA risk, such as actively reducing body weight by for example following a low carbohydrate restriction or ketogenic diet or engaging in the use of excessive alcohol (i.e. drinking more than the current UK guidelines of 14 units a week) and/or illicit drugs, should not receive dapagliflozin.

Given that SGLT2 inhibitors are not approved in pregnancy and that DKA during pregnancy is associated with significant maternal and foetal mortality $[55,56]$, dapagliflozin should not be prescribed to females with T1DM who are pregnant or planning pregnancy or who are unwilling to use appropriate contraceptives to avoid pregnancy.

Dapagliflozin should not be prescribed to people with T1DM with GFR $<60 \mathrm{ml} / \mathrm{min} /$ $1.73 \mathrm{~m}^{2}$. This recommendation is not based on concerns of safety but due to the efficacy of dapagliflozin, which has not been demonstrated in those with poor renal function.

As there are limited data on the use of SGLT2 inhibitors in those $<18$ years or $\geq 75$ years we do not recommend dapagliflozin in these age groups.

\section{APPROACHES IN ROUTINE CLINICAL PRACTICE}

When using dapagliflozin in routine clinical practise there are a number of issues to consider to mitigate the risks associated with this treatment.

Education regarding the risks of minor adverse events such as mycotic genital infections and UTIs should be provided to people with T1DM when initiating dapagliflozin treatment. This may encourage people to self-monitor treatment efficacy and adverse effects and help them manage these infections. People should also be made aware of the risk of Fournier's gangrene, a rare but serious and potentially life-threatening infection, which has been associated with the use of SGLT2 inhibitors, and they should be informed of additional risk factors that may increase their risk of this infection, including for example poor personal hygiene, alcohol abuse and obesity [57, 58]. People should be advised to seek urgent medical attention if they experience severe pain, tenderness, erythaema or swelling in the genital or perineal area, accompanied by fever or malaise. If Fournier's gangrene is suspected, clinicians are advised to stop dapagliflozin and urgently start appropriate treatment, including the administration of broad-spectrum intravenous antibiotics and surgical removal of extensive areas of necrosis.

An increased risk of DKA has been associated with the use of dapagliflozin, with inadequate 
insulin dose being reported as the most common risk factor. Therefore, individuals who are relatively insulin deficient, have sudden reductions in insulin dose or have an increased requirement for insulin (due to illness, surgery or alcohol abuse) should be closely monitored. Education of both people with T1DM and healthcare professionals will play a crucial role in reducing the risk of DKA associated with dapagliflozin use. This should include the provision of relevant information in both oral and written forms. A person-centred information leaflet covering the key messages should be provided for the person to take away and refer to when needed. It is important for those with T1DM as well as healthcare professionals to be aware that DKA associated with the use of dapagliflozin may not present typically and that glucose levels may be relatively normal, a condition referred to as normoglycemic DKA or euglycemic DKA [59]. Thus, we recommend testing for raised blood ketone levels when DKA symptoms are present, or during bouts of minor illness, even if blood glucose levels are within the normal range.

Prior to initiation with dapagliflozin people with T1DM should be re-educated on their condition and should also undergo formal structured education focussed on mitigating the risk of DKA. An example of a healthcare professional checklist that may be used in relation to the use of dapagliflozin in people with T1DM, and which advises on information to be included in an education session, is provided in the Appendix in the electronic supplementary material. The risks associated with dapagliflozin treatment should be fully explained, but balanced against the positive impact on $\mathrm{HbA1c}$, weight and time in optimal glucose range. People should be informed of the symptoms of DKA (rapid weight loss, nausea or vomiting, stomach pain, excessive thirst, fast and deep breathing, confusion, unusual sleepiness or tiredness, a sweet smell to the breath, a sweet or metallic taste in the mouth, or a different odour to urine or sweat), emphasising that DKA may occur even if blood glucose levels are within the normal range. Information should also be provided regarding DKA risk factors and the importance of ketone monitoring.
Very-low-calorie diets and ketogenic diets are increasingly popular dietary approaches to induce rapid weight loss, but are associated with an increased risk of DKA in people with T1DM. Therefore, anyone commencing on dapagliflozin should be strongly advised against such weight loss strategies and should also be educated regarding the importance of avoiding other important pro-ketogenic factors such as missed insulin doses.

People should also be educated on the management of blood glucose during periods of illness ('sick-day management'). This should include specific information regarding the frequency of blood glucose monitoring, blood glucose targets, blood ketone monitoring, appropriate adjustment of insulin doses and identifying early signs and symptoms of DKA. To complement the education, people with T1DM should be provided with the TREND-UK patient information leaflet 'Type 1 diabetes: What to do when you are ill' [60]. People should be reminded of the seriousness of DKA and advised to discontinue dapagliflozin and call their GP or diabetes team, or go to the nearest accident and emergency (A\&E) hospital, if they develop any DKA symptoms.

Education to support healthcare professionals to understand and manage the risk of DKA in people with T1DM and in helping people to recognise and respond appropriately to symptoms is important. Even though initiation of dapagliflozin treatment is by specialists, ongoing prescribing and monitoring will be performed in the community. Hence GPs, A\&E staff and specialist healthcare professionals should all receive dapagliflozin education. Considerations such as blood ketone monitoring, sick-day rules, mycotic genital infection/ UTI risk, DKA advice and appropriate reductions in insulin dose will be important education topics. An information leaflet for healthcare professionals similar to TREND-UKs 'Appropriate use of SGLT2 inhibitors in type 2 diabetes: right person, right medication, right time' [61] but focussed on T1DM would be considered a useful resource.

Regarding blood ketone monitoring, for the first week following dapagliflozin initiation monitoring should be once a day then the 
frequency of routine monitoring should be individualised based on specific risk factors. Blood ketone levels should also be checked in situations that may increase the risk of DKA, and people with T1DM and healthcare staff should be advised regarding actions to be taken in cases of raised ketone levels. The STOP DKA protocol is considered a useful strategy if ketone levels become increased during treatment with dapagliflozin and to prevent progression to DKA [62]. The protocol builds on the STICH protocol [63] and provides a risk mitigation strategy to follow when symptoms of DKA develop, which includes never stopping insulin, stopping the SGLT inhibitor, keeping hydrated and taking supplemental insulin and carbohydrates every $2-4 \mathrm{~h}$ according to blood ketone and glucose levels as per the STOP DKA table. Blood ketone levels should be reassessed and emergency medical care sought if ketones levels remain increased or if DKA symptoms present.

\section{PRACTICAL APPROACHES FOR DAPAGLIFLOZIN TREATMENT IN T1DM}

People with T1DM considered eligible for dapagliflozin treatment (those meeting the criteria listed in the green section of Fig. 1) should undergo routine safety and efficacy monitoring following dapagliflozin initiation. We suggest that this includes hypoglycaemia frequency, insulin dose requirement, weight change and Hb1Ac. HbA1c provides only an approximate measure of glucose control and does not address glucose fluctuations. The introduction of CGM has enabled a more relevant end point for assessing glycaemic control to be recorded, i.e. time in range [the percentage of time a person's glucose level is within $70-180 \mathrm{mg} / \mathrm{dl}(3.9-10 \mathrm{mmol} / \mathrm{l})$ ] [64-66]. Time in range is inversely correlated to the risk of developing micro- and macrovascular complications and quality of life [67]. Therefore, we also recommend that time in range is recorded, using either CGM systems or frequent capillary blood glucose monitoring, for people with T1DM receiving dapagliflozin treatment.

When initiating dapagliflozin treatment we recommend insulin dose reduction, basal or prandial, based on an assessment of an individual's glucose monitoring data. If there are concerns around nocturnal hypoglycaemia basal insulin should be reduced, whilst mealtime insulin should be reduced if there are concerns around post prandial hypoglycaemia. Insulin dose reduction should not exceed 20\% to avoid DKA.

In cases of acute illness (with the exception of minor illnesses such as colds), injury, planned medical or surgical procedures requiring starvation, very low calorie diets, missed meals, stress, excessive exercise (long duration and/or high intensity exercise sessions), dehydration, missed or significantly reduced insulin dose, insulin pump malfunction or occlusion, and use of illicit drugs or excessive alcohol, dapagliflozin should be discontinued until the person's condition has stabilised and ketone levels are consistently $<0.6 \mathrm{mmol} / \mathrm{l}$.

Anyone on dapagliflozin who presents with symptoms suggestive of DKA should have their blood ketone concentrations checked regardless of their blood glucose concentration. Dapagliflozin should be discontinued immediately if DKA is suspected or diagnosed. The management of DKA involves administering intravenous fluids to correct dehydration and to replace any salts that may be lost during ketoacidosis through passing excessive quantities of urine [68]. Insulin is also required to suppress the ketone bodies. People should be monitored for complications of DKA and its treatment, for example cerebral oedema, hypokalaemia, hyperkalaemia and hypoglycaemia. Dapagliflozin should not be restarted in those who experienced DKA during use, unless another cause for DKA is identified and resolved.

\section{SUMMARY}

Whilst insulin remains the mainstay of treatment for T1DM, many people with T1DM are unable to meet their glycaemic targets with insulin treatment alone. Results from the DEPICT clinical trial programme have demonstrated the SGLT2 inhibitor dapagliflozin to be an effective adjunct therapy with the potential 
to enable more people with T1DM to achieve their glycaemic goals. These results have led to dapagliflozin being the first oral treatment approved in Europe and having NICE and SMC approval as an adjunct to insulin for people with T1DM whose glucose levels are not adequately controlled with insulin alone. However, not all people with T1DM are suitable for dapagliflozin treatment and individual characteristics need to be considered when initiating dapagliflozin to mitigate DKA risk. To aid clinicians in selecting appropriate people for dapagliflozin treatment we have developed a traffic light system checklist. Those most likely to benefit from dapagliflozin treatment include overweight/obese people, established on stable optimised insulin therapy, with a low DKA risk profile, that have demonstrated adherence to their insulin regimen and the ability to understand and utilise relevant education relating to DKA risk and risk mitigation strategies. Dapagliflozin should be avoided in people with T1DM with low insulin needs, who are at high risk of DKA, have difficulty adhering to their insulin regimen or have difficulty understanding and following treatment instructions.

The guidance presented here provides a valuable reference for healthcare professionals contributing to diabetes treatment and care in the UK, offering expert consensus advice regarding appropriate prescribing, as well as approaches in routine clinical practice and practical approaches, for dapagliflozin treatment in T1DM.

\section{ACKNOWLEDGEMENTS}

AstraZeneca UK Ltd. has reviewed this document for factual accuracy only.

Funding. Sponsorship for this work and the journal's Rapid Service Fee were funded by AstraZeneca UK Ltd.

Editorial Assistance. Editorial assistance in the preparation of this article was provided by Dr Angharad R. Morgan of Health Economics and Outcomes Research Ltd. Support for this assistance was funded by AstraZeneca UK Ltd.

Authorship. All named authors meet the International Committee of Medical Journal Editors (ICMJE) criteria for authorship for this article, take responsibility for the integrity of the work as a whole, and have given their approval for this version to be published.

Disclosures. Marc Evans has received honoraria and research awards from Novo Nordisk, AstraZeneca, Novartis, BI, Sunovion and Novartis. Debbie Hicks has received honoraria for attendance at advisory boards, delivering educational presentations and sponsorship to attend scientific meetings from AstraZeneca, Boehringer-Ingelhiem, B Braun, BD, GlucoRx, Lilly, MSD, Mylan, Napp, Novo Nordisk, Owen Mumford, Roche, Sanofi and Takeda. Debbie Hicks is a Co-Chair of TREND-UK. Dipesh Patel has received educational or research sponsorship, and speaker or advisory related honoraria, from AstraZeneca, Boehringer Ingelheim, Lilly, MSD, Napp Pharmaceuticals Ltd, Novo Nordisk, Sanofi and Takeda. Vinod Patel has worked with AstraZeneca, Boehringer Ingelheim, Eli-Lily, MSD, Napp and Novo-Nordisk Takeda in relation to diabetes care education with occasional advisory board work and has also obtained travel arrangements for conferences in diabetes care. Phil McEwan is an employee of Health Economics and Outcomes Research Ltd., Cardiff, UK, who received fees from AstraZeneca in relation to this study. Umesh Dashora has received lecture fees from AstraZeneca for educational sessions for medical representatives and health professionals.

Compliance with Ethics Guidelines. This article is based on previously conducted studies and does not contain any studies with human participants or animals performed by any of the authors.

Data Availability. Data sharing is not applicable to this article as no datasets were generated or analysed during the current study. 
Open Access. This article is distributed under the terms of the Creative Commons Attribution-NonCommercial 4.0 International License (http://creativecommons.org/licenses/ by-nc/4.0/), which permits any noncommercial use, distribution, and reproduction in any medium, provided you give appropriate credit to the original author(s) and the source, provide a link to the Creative Commons license, and indicate if changes were made.

\section{REFERENCES}

1. Maahs DM, West NA, Lawrence JM, Mayer-Davis EJ. Epidemiology of type 1 diabetes. Endocrinol Metab Clin North Am. 2010;39(3):481-97. https://doi.org/ 10.1016/j.ecl.2010.05.011.

2. Mayer-Davis EJ, Lawrence JM, Dabelea D, Divers J, Isom $\mathrm{S}$, Dolan $\mathrm{L}$, et al. Incidence trends of type 1 and type 2 diabetes among youths, 2002-2012. N Engl J Med. 2017;376(15):1419-29. https://doi. org/10.1056/NEJMoa1610187.

3. Atkinson MA, Maclaren NK. The pathogenesis of insulin-dependent diabetes mellitus. N Engl J Med. 1994;331(21):1428-36. https://doi.org/10.1056/ nejm199411243312107.

4. Katsarou A, Gudbjornsdottir S, Rawshani A, Dabelea D, Bonifacio E, Anderson BJ, et al. Type 1 diabetes mellitus. Nat Rev Dis Primers. 2017;3:17016. https://doi.org/10.1038/nrdp.2017.16.

5. DiMeglio LA, Evans-Molina C, Oram RA. Type 1 diabetes. Lancet (London, England). 2018;391(10138):2449-62. https://doi.org/10.1016/ s0140-6736(18)31320-5.

6. Nathan DM, Genuth S, Lachin J, Cleary P, Crofford $\mathrm{O}$, Davis $\mathrm{M}$, et al. The effect of intensive treatment of diabetes on the development and progression of long-term complications in insulin-dependent diabetes mellitus. N Engl J Med. 1993;329(14):977-86. https://doi.org/10.1056/nejm199309303291401.

7. Lachin JM, Genuth S, Cleary P, Davis MD, Nathan DM. Retinopathy and nephropathy in patients with type 1 diabetes four years after a trial of intensive therapy. N Engl J Med. 2000;342(6):381-9. https:// doi.org/10.1056/nejm200002103420603.

8. Nathan DM, McGee P, Steffes MW, Lachin JM. Relationship of glycated albumin to blood glucose and HbA1c values and to retinopathy, nephropathy, and cardiovascular outcomes in the DCCT/
EDIC study. Diabetes. 2014;63(1):282-90. https:// doi.org/10.2337/db13-0782.

9. American Diabetes Association. (7) Approaches to glycemic treatment. Diabetes Care. 2015;38(Suppl): S41-8. https://doi.org/10.2337/dc15-S010.

10. Peters AL, Ahmann AJ, Battelino T, Evert A, Hirsch IB, Murad MH, et al. Diabetes technology-continuous subcutaneous insulin infusion therapy and continuous glucose monitoring in adults: an Endocrine Society clinical practice guideline. J Clin Endocrinol Metab. 2016;101(11):3922-37. https:// doi.org/10.1210/jc.2016-2534.

11. Diabetes Control and Complications Trial Research Group. Hypoglycemia in the diabetes control and complications trial. The diabetes control and complications trial research group. Diabetes. 1997;46(2):271-86.

12. The DCCT Research Group. Weight gain associated with intensive therapy in the diabetes control and complications trial. The DCCT Research Group. Diabetes Care. 1988;11(7):567-73. https://doi.org/ 10.2337/diacare.11.7.567.

13. Gubitosi-Klug RA, Braffett BH, White NH, Sherwin RS, Service FJ, Lachin JM. Risk of severe hypoglycemia in type 1 diabetes over 30 years of followup in the DCCT/EDIC Study. Diabetes Care. 2017;40(8):1010-6.

14. Tamborlane WV. Severe hypoglycemia in youth with T1DM: going, going ... but not yet gone. Pediatr Diabetes. 2011;12(1):1-3. https://doi.org/ 10.1111/j.1399-5448.2010.00754.x.

15. Beall C, Ashford ML, McCrimmon RJ. The physiology and pathophysiology of the neural control of the counterregulatory response. Am J Phys Regul Integr Comp Phys. 2012;302(2):R215-23. https:// doi.org/10.1152/ajpregu.00531.2011.

16. NHS Digital. National Diabetes Audit 2017-18. Report 1: Care Processes and Treatment Targets. 2019. https://digital.nhs.uk/data-and-information/ publications/statistical/national-diabetes-audit/rep ort-1-care-processes-and-treatment-targets-2017-18full-report. Accessed 24 July 2019.

17. Petrie JR, Chaturvedi N, Ford I, Brouwers M, Greenlaw N, Tillin T, et al. Cardiovascular and metabolic effects of metformin in patients with type 1 diabetes (REMOVAL): a double-blind, randomised, placebo-controlled trial. Lancet Diabetes Endocrinol. 2017;5(8):597-609. https://doi.org/10. 1016/s2213-8587(17)30194-8.

18. Meng H, Zhang A, Liang Y, Hao J, Zhang X, Lu J. Effect of metformin on glycaemic control in patients with type 1 diabetes: a meta-analysis of 
randomized controlled trials. Diabetes/Metab Res Rev. 2018;34(4):e2983. https://doi.org/10.1002/ dmrr.2983.

19. Schopman JE, Hoekstra JB, Frier BM, Ackermans MT, de Sonnaville JJ, Stades AM, et al. Effects of sitagliptin on counter-regulatory and incretin hormones during acute hypoglycaemia in patients with type 1 diabetes: a randomized double-blind placebo-controlled crossover study. Diabetes Obes Metab. 2015;17(6):546-53. https://doi.org/10.1111/ dom.12453.

20. Farngren J, Persson M, Schweizer A, Foley JE, Ahren B. Vildagliptin reduces glucagon during hyperglycemia and sustains glucagon counterregulation during hypoglycemia in type 1 diabetes. J Clin Endocrinol Metab. 2012;97(10):3799-806. https:// doi.org/10.1210/jc.2012-2332.

21. Garg SK, Moser EG, Bode BW, Klaff LJ, Hiatt WR, Beatson C, et al. Effect of sitagliptin on post-prandial glucagon and GLP-1 levels in patients with type 1 diabetes: investigator-initiated, double-blind, randomized, placebo-controlled trial. Endocr Pract. 2013;19(1):19-28. https://doi.org/10.4158/ ep12100.Or.

22. Guo H, Fang C, Huang Y, Pei Y, Chen L, Hu J. The efficacy and safety of DPP4 inhibitors in patients with type 1 diabetes: a systematic review and metaanalysis. Diabetes Res Clin Pract. 2016;121:184-91. https://doi.org/10.1016/j.diabres.2016.08.022.

23. Mathieu C, Zinman B, Hemmingsson JU, Woo V, Colman P, Christiansen E, et al. Efficacy and safety of liraglutide added to insulin treatment in type 1 diabetes: the ADJUNCT ONE treat-to-target randomized trial. Diabetes Care. 2016;39(10):1702-10. https://doi.org/10.2337/dc16-0691.

24. Ahren B, Hirsch IB, Pieber TR, Mathieu C, GomezPeralta F, Hansen TK, et al. Efficacy and safety of liraglutide added to capped insulin treatment in subjects with type 1 diabetes: the ADJUNCT TWO randomized trial. Diabetes Care. 2016;39(10): 1693-701. https://doi.org/10.2337/dc16-0690.

25. Liu L, Shao Z, Xia Y, Qin J, Xiao Y, Zhou Z, et al. Incretin-based therapies for patients with type 1 diabetes: a meta-analysis. Endocr Connect. 2019. https://doi.org/10.1530/ec-18-0546.

26. DeGeeter M, Williamson B. Alternative Agents in Type 1 Diabetes in Addition to Insulin Therapy: Metformin, Alpha-Glucosidase Inhibitors, Pioglitazone, GLP-1 Agonists, DPP-IV Inhibitors, and SGLT2 Inhibitors. J Pharm Pract. 2016;29(2):144-59. https://doi.org/10.1177/0897190014549837.

27. Hari Kumar KV, Shaikh A, Prusty P. Addition of exenatide or sitagliptin to insulin in new onset type
1 diabetes: a randomized, open label study. Diabetes Res Clin Pract. 2013;100(2):e55-8. https://doi. org/10.1016/j.diabres.2013.01.020.

28. Ellis SL, Moser EG, Snell-Bergeon JK, Rodionova AS, Hazenfield RM, Garg SK. Effect of sitagliptin on glucose control in adult patients with Type 1 diabetes: a pilot, double-blind, randomized, crossover trial. Diabetic Med. 2011;28(10):1176-81. https:// doi.org/10.1111/j.1464-5491.2011.03331.x.

29. Griffin KJ, Thompson PA, Gottschalk M, Kyllo JH, Rabinovitch A. Combination therapy with sitagliptin and lansoprazole in patients with recentonset type 1 diabetes (REPAIR-T1D): 12-month results of a multicentre, randomised, placebo-controlled, phase 2 trial. Lancet Diabetes Endocrinol. 2014;2(9):710-8. https://doi.org/10.1016/s2213$8587(14) 70115-9$.

30. Zhao Y, Yang L, Xiang Y, Liu L, Huang G, Long Z, et al. Dipeptidyl peptidase 4 inhibitor sitagliptin maintains beta-cell function in patients with recent-onset latent autoimmune diabetes in adults: one year prospective study. J Clin Endocrinol Metab. 2014;99(5):E876-80. https://doi.org/10. 1210/jc.2013-3633.

31. Ferrannini E, Solini A. SGLT2 inhibition in diabetes mellitus: rationale and clinical prospects. Nat Rev Endocrinol. 2012;8(8):495-502. https://doi.org/10. 1038/nrendo.2011.243.

32. Jurczak MJ, Lee HY, Birkenfeld AL, Jornayvaz FR, Frederick DW, Pongratz RL, et al. SGLT2 deletion improves glucose homeostasis and preserves pancreatic beta-cell function. Diabetes. 2011;60(3): 890-8. https://doi.org/10.2337/db10-1328.

33. Vallon V. The mechanisms and therapeutic potential of SGLT2 inhibitors in diabetes mellitus. Annu Rev Med. 2015;66:255-70. https://doi.org/10.1146/ annurev-med-051013-110046.

34. Rosenstock J, Marquard J, Laffel LM, Neubacher D, Kaspers S, Cherney DZ, et al. Empagliflozin as adjunctive to insulin therapy in type 1 diabetes: the EASE trials. Diabetes Care. 2018;41(12):2560-9. https://doi.org/10.2337/dc18-1749.

35. Buse JB, Garg SK, Rosenstock J, Bailey TS, Banks P, Bode BW, et al. Sotagliflozin in combination with optimized insulin therapy in adults with type 1 diabetes: the North American inTandem1 study. Diabetes Care. 2018;41(9):1970-80. https://doi.org/ 10.2337/dc18-0343.

36. Danne T, Cariou B, Banks P, Brandle M, Brath $\mathrm{H}$, Franek E, et al. HbA1c and hypoglycemia reductions at 24 and 52 weeks with sotagliflozin in combination with insulin in adults with type 1 diabetes: the European inTandem2 study. Diabetes 
Care. 2018;41(9):1981-90. https://doi.org/10.2337/ dc18-0342.

37. Garg SK, Henry RR, Banks P, Buse JB, Davies MJ, Fulcher GR, et al. Effects of sotagliflozin added to insulin in patients with type 1 diabetes. $\mathrm{N}$ Engl J Med. 2017;377(24):2337-48. https://doi.org/10. 1056/NEJMoa1708337.

38. Dandona P, Mathieu C, Phillip M, Hansen L, Griffen SC, Tschope D, et al. Efficacy and safety of dapagliflozin in patients with inadequately controlled type 1 diabetes (DEPICT-1): 24 week results from a multicentre, double-blind, phase 3, randomised controlled trial. Lancet Diabetes Endocrinol. 2017;5(11):864-76. https://doi.org/10.1016/ s2213-8587(17)30308-X.

39. Dandona P, Mathieu C, Phillip M, Hansen L, Tschope D, Thoren F, et al. Efficacy and safety of dapagliflozin in patients with inadequately controlled type 1 diabetes: the DEPICT-1 52-week study. Diabetes Care. 2018;41(12):2552-9. https:// doi.org/10.2337/dc18-1087.

40. Mathieu C, Dandona P, Gillard P, Senior P, Hasslacher C, Araki E, et al. Efficacy and safety of dapagliflozin in patients with inadequately controlled type 1 diabetes (the DEPICT-2 study): 24-week results from a randomized controlled trial. Diabetes Care. 2018;41(9):1938-46. https://doi.org/ $10.2337 /$ dc18-0623.

41. Mathieu C, Dandona P, Phillip M, Oron T, Lind M, Hansen $\mathrm{L}$, et al. Glucose variables in type 1 diabetes studies with dapagliflozin: pooled analysis of continuous glucose monitoring data from DEPICT-1 and -2. Diabetes Care. 2019;42(6):1081-7. https:// doi.org/10.2337/dc18-1983.

42. Dashora U, Patel D, Gregory R, Winocour P, Dhatariya K, Nagi D. Association of British Clinical Diabetologists (ABCD) position statement on the use of sodium-glucose cotransporter- 2 inhibitors in type 1 diabetes (updated 2019). Br J Diabetes. 2019;19:66-72.

43. Danne T, Garg S, Peters AL, Buse JB, Mathieu C, Pettus $\mathrm{JH}$, et al. International consensus on risk management of diabetic ketoacidosis in patients with type 1 diabetes treated with sodium-glucose cotransporter (SGLT) inhibitors. Diabetes Care. 2019;42(6):1147-54. https://doi.org/10.2337/dc182316.

44. Aguillón AR, Mascarello A, Segretti ND, de Azevedo HFZ, Guimaraes CRW, Miranda LSM, et al. Synthetic strategies toward SGLT2 inhibitors. Org Process Res Dev. 2018;22:467-88.

45. European Pharmaceutical Review. EMA accepts marketing authorisation variation for Forxiga in adults with type-1 diabetes 2019. https://www. europeanpharmaceuticalreview.com/news/73381/ ema-forxiga-type-1-diabetes/. Accessed 24 July 2019.

46. National Institute for Health and Clinical Excellence. Technology appraisal guidance [TA597]: Dapagliflozin with insulin for treating type 1 diabetes 2019. https://www.nice.org.uk/guidance/ TA597. Accessed 1 Sept 2019.

47. Scottish Medicine Consortium. SMC2185: Dapagliflozin $5 \mathrm{mg}$ film coated tablets (Forxiga ${ }^{\circledR}$ ) for treating Type 1 diabetes 2019. https://www.scottish medicines.org.uk/medicines-advice/dapagliflozinforxiga-full-smc2185/. Accessed 9 Sept 2019.

48. Danne T, Cariou B, Buse JB, Garg SK, Rosenstock J, Banks $P$, et al. improved time in range and glycemic variability with sotagliflozin in combination with insulin in adults with type 1 diabetes: a pooled analysis of 24-week continuous glucose monitoring data from the intandem program. Diabetes Care. 2019;42(5):919-30. https://doi.org/10.2337/dc182149.

49. European Medicines Agency. Forxiga : EPAR medicine overview 2019. https://www.ema.europa. eu/en/documents/overview/forxiga-epar-medicineoverview_en.pdf. Accessed 1 Sept 2019.

50. Battelino T, Danne T, Bergenstal RM, Amiel SA, Beck R, Biester T, et al. Clinical targets for continuous glucose monitoring data interpretation: recommendations from the international consensus on time in range. Diabetes Care. 2019. https://doi. org/10.2337/dci19-0028.

51. Lega IC, Bronskill SE, Campitelli MA, Guan J, Stall NM, Lam K, et al. Sodium glucose cotransporter 2 inhibitors and risk of genital mycotic and urinary tract infection: a population-based study of older women and men with diabetes. Diabetes Obes Metab. 2019. https://doi.org/10.1111/dom.13820.

52. Bersoff-Matcha SJ, Chamberlain C, Cao C, Kortepeter C, Chong WH. Fournier gangrene associated with sodium-glucose cotransporter- 2 inhibitors: a review of spontaneous postmarketing cases. Ann Intern Med. 2019;170(11):764-9. https://doi.org/ 10.7326/m19-0085.

53. Patel NS, Van Name MA, Cengiz E, Carria LR, Weinzimer SA, Tamborlane WV, et al. Altered patterns of early metabolic decompensation in type 1 diabetes during treatment with a SGLT2 inhibitor: an insulin pump suspension study. Diabetes Technol Therap. 2017;19(11):618-22. https://doi.org/10. 1089/dia.2017.0267.

54. Dhatariya K. Blood ketones: measurement, interpretation, limitations, and utility in the 
management of diabetic ketoacidosis. Rev Diabet Stud. 2016;13(4):217-25. https://doi.org/10.1900/ rds.2016.13.217.

55. Kamalakannan D, Baskar V, Barton DM, Abdu TA. Diabetic ketoacidosis in pregnancy. Postgrad Med J. 2003;79(934):454-7. https://doi.org/10.1136/pmj. 79.934.454.

56. Morrison FJR, Movassaghian M, Seely EW, Curran A, Shubina M, Morton-Eggleston E, et al. Fetal outcomes after diabetic ketoacidosis during pregnancy. Diabetes Care. 2017;40(7):e77-9. https:// doi.org/10.2337/dc17-0186.

57. Wang YK, Li YH, Wu ST, Meng E. Fournier's gangrene. QJM. 2017;110(10):671-2. https://doi.org/ 10.1093/qjmed/hcx124.

58. Yanar H, Taviloglu K, Ertekin C, Guloglu R, Zorba U, Cabioglu N, et al. Fournier's gangrene: risk factors and strategies for management. World J Surg. 2006;30(9): 1750-4. https://doi.org/10.1007/s00268-005-0777-3.

59. Rosenstock J, Ferrannini E. Euglycemic diabetic ketoacidosis: a predictable, detectable, and preventable safety concern with SGLT2 inhibitors. Diabetes Care. 2015;38(9):1638-42. https://doi.org/ 10.2337/dc15-1380.

60. Trend UK. Type 1 diabetes: What to do when you are ill 2018. http://trend-uk.org/wp-content/ uploads/2018/03/A5_T1Illness_TREND_FINAL.pdf. Accessed 24 July 2019.

61. Trend UK. For healthcare professionals: Appropriate use of SGLT2 inhibitors in type 2 diabetes: right person, right medication, right time 2018. https:// www.mydiabetesmyway.scot.nhs.uk/admin/Uploa dedFiles/Napp-HCP_SGLT2_TREND_FINAL.pdf. Accessed 24 July 2019.

62. Goldenberg RM, Gilbert JD, Hramiak IM, Woo VC, Zinman B. Sodium-glucose co-transporter inhibitors, their role in type 1 diabetes treatment and a risk mitigation strategy for preventing diabetic ketoacidosis: The STOP DKA Protocol. Diabetes Obes Metab. 2019;21(10):2192-202. https:// doi.org/10.1111/dom.13811.

63. Garg SK, Peters AL, Buse JB, Danne T. Strategy for mitigating DKA risk in patients with type 1 diabetes on adjunctive treatment with SGLT inhibitors: A STICH protocol. Diabetes Technol Therap. 2018;20(9):571-5. https://doi.org/10.1089/dia. 2018.0246.

64. Beck RW, Bergenstal RM, Riddlesworth TD, Kollman C, Li Z, Brown AS, et al. Validation of time in range as an outcome measure for diabetes clinical trials. Diabetes Care. 2019;42(3):400-5. https://doi. org/10.2337/dc18-1444.

65. Ceriello A, Kilpatrick ES. Glycemic variability: both sides of the story. Diabetes Care. 2013;36(Suppl 2): S272-5. https://doi.org/10.2337/dcS13-2030.

66. Ayano-Takahara S, Ikeda K, Fujimoto S, Hamasaki A, Harashima S, Toyoda K, et al. Glycemic variability is associated with quality of life and treatment satisfaction in patients with type 1 diabetes. Diabetes Care. 2015;38(1):e1-2. https://doi.org/10. 2337/dc14-1801.

67. Lu J, Ma X, Zhou J, Zhang L, Mo Y, Ying L, et al. Association of time in range, as assessed by continuous glucose monitoring, with diabetic retinopathy in type 2 diabetes. Diabetes Care. 2018;41(11):2370-6. https://doi.org/10.2337/dc181131.

68. Savage MW, Dhatariya KK, Kilvert A, Rayman G, Rees JA, Courtney $\mathrm{CH}$, et al. Joint British Diabetes Societies guideline for the management of diabetic ketoacidosis. Diabet Med. 2011;28(5):508-15. https://doi.org/10.1111/j.1464-5491.2011.03246.x. 